\title{
Hydrothermal Dissolution of Opal in Sodium Hydroxide Lyes for the Synthesis of Water Glass
}

\author{
Thomas Pfeiffer ${ }^{1,2}$, Dirk Enke ${ }^{3}$, Robert Roth ${ }^{4}$, Hans Roggendorf ${ }^{4}{ }^{*}$ \\ ${ }^{1}$ Institute of Physics, Martin-Luther-University Halle-Wittenberg, Halle, Germany \\ ${ }^{2}$ OPTERRA Zement GmbH, Karsdorf, Germany \\ ${ }^{3}$ Institute of Chemical Technology, University of Leipzig, Leipzig, Germany \\ ${ }^{4}$ Institute of Physics, Martin-Luther-University Halle-Wittenberg, Halle, Germany \\ Email: *hans.roggendorf@physik.uni-halle.de
}

How to cite this paper: Pfeiffer, T., Enke, D., Roth, R. and Roggendorf, H. (2017) Hydrothermal Dissolution of Opal in Sodium Hydroxide Lyes for the Synthesis of Water Glass. Advances in Chemical Engineering and Science, 7, 76-90.

http://dx.doi.org/10.4236/aces.2017.71007

Received: December 13, 2016

Accepted: January 16, 2017

Published: January 19, 2017

Copyright $\odot 2017$ by authors and Scientific Research Publishing Inc. This work is licensed under the Creative Commons Attribution International License (CC BY 4.0).

http://creativecommons.org/licenses/by/4.0/ cc) (i) Open Access

\begin{abstract}
Common opal was dissolved in $\mathrm{NaOH}$ lyes in rotating autoclaves. The starting material was characterized by X-ray diffraction and adsorption spectroscopy, thermal and chemical analysis, electron and atomic force microscopy. The opal proved to be an Opal-CT with a microstructure consisting of microcrystalline tridymite, traces of low-quartz, and amorphous parts built up by random packings of size distributed amorphous silica colloids. The dissolution conditions have been inspired by the technological process of hydrothermal water glass synthesis by dissolving silica. Temperature and time of the dissolution process as well as initial molar $\mathrm{SiO}_{2}: \mathrm{Na}_{2} \mathrm{O}$ $\left(\mathrm{R}_{\mathrm{m}}\right)$ ratios of the starting materials were varied systematically. The particle size of the samples was varied, too, but due to the nanoscopic microstructure without greater impact on dissolution kinetics. The process products were analyzed chemically. Additionally, some of them were characterized by X-ray diffraction, viscosimetry and dynamic light scattering. Already after short dissolution times, water glasses with quite high silica concentrations of up to $27 \mathrm{wt} . \%$ and $\mathrm{SiO}_{2}: \mathrm{Na}_{2} \mathrm{O}$ ratios of up to 3.7 were obtained. At longer dissolution times low-quartz and analcime precipitated and the $\mathrm{SiO}_{2}$ contents were reduced to about $22 \mathrm{wt} . \%$ and $\mathrm{R}_{\mathrm{m}}$ to about 2.7. The silica contents in equilibrium with low-quartz were almost independent on temperature.
\end{abstract}

\section{Keywords}

Water Glass, Opal, Silica, Hydrothermal Dissolution

\section{Introduction}

The term water glass not only describes alkali-rich silicate glasses but also the liquid phases obtained either when these glasses are dissolved into water or when a silica phase is dissolved in alkaline lyes. Commercially available liquid sodium water glasses 
have compositions characterised by a molar $\mathrm{SiO}_{2}: \mathrm{Na}_{2} \mathrm{O}$ ratio $\left(\mathrm{R}_{\mathrm{m}}\right)$ of 1.8 to 4 (ratios of 2.0 and 3.3 are standard compositions) and a $\mathrm{SiO}_{2}$ content of 25 wt.\% to 30 wt.\% (Weldes and Lange [1]).

The hydrothermal dissolution of silica materials in sodium lyes is one of the two standard methods for the production of water glasses. The concurring method is dissolving alkaline silicate glasses in $\mathrm{H}_{2} \mathrm{O}$ at elevated temperatures up to $150^{\circ} \mathrm{C}$. The hydrothermal dissolution of silica is usually restricted to compositions with $\mathrm{R}_{\mathrm{m}}<2.7$ [1]. Possibly, these concentration limitations are due to chemical saturation. Higher $\mathrm{R}_{\mathrm{m}}$ values can be obtained when raw materials with higher reactivities like cristobalite or vitreous silica are used. Hydrothermal dissolution of silica materials requires less energy and thus causes lower $\mathrm{CO}_{2}$ output during production.

The solubility of silica phases is an important topic of silicate chemistry and geochemistry. Solubility of silica at higher $\mathrm{pH}$ and temperatures is also important for process technologies concerned with the production of liquid water glasses. The older literature on the solubility of silica was evaluated by Iler [2]. The solubility of silica depends on the solid equilibrium phase coexisting with the aqueous liquid, as well as on temperature, pressure, and $\mathrm{pH}$ of the dissolution process and on the particle size of the dissolving silica phase. Iler [2] refers to the work of Stöber [3] that at nearly neutral conditions the solubility of silica decreases in the order of vitreous silica $>$ stishovite $>$ cristobalite $>$ tridymite $>$ quartz $>$ coesite.

The conditions of hydrothermal dissolution in sodium hydroxide comprise elevated temperatures (above $100^{\circ} \mathrm{C}$ ) and pressures (Dove et al. [4]) as well as high $\mathrm{pH}$ values. Temperature and pressure enhance solubility of silica, whereas the effects of pressure are in most cases not separated from temperature. Fleming et al. [5] calculated the silica solubility at temperatures up to $300^{\circ} \mathrm{C}$ and $\mathrm{pH}$ values up to 12 in equilibrium with quartz or amorphous silica by thermodynamic means and reported solubilities up to 3 mole $\mathrm{SiO}_{2} / 1$. Further results for higher temperatures and pressures are found in publications connected with geochemistry (Gunnarsson et al. [6]), or in phase diagrams (e.g. Tuttle et al. [7]).

Opals are minerals with silica as main component. They can be regarded as an impure silica source with a higher reactivity than ordinary quartz or even vitreous silica. According to Iler [2] the term "opal” covers many types of hydrated amorphous silicas. Amorphous means here the absence of sharp X-ray diffraction peaks. But the presence of submicroscopic crystallites like cristobalite or tridymite is possible. Opals were classified by Jones and Segnit [8] according to their structure:

Opal-A: Amorphous materials of either monosized silica colloids forming an ordered microstructure (precious opal) or size distributed statistically packed colloids (sometimes called potch). The ordered microstructures resemble crystal lattices and may serve as Bragg lattices for optical light, making them suitable as gemstones.

Opal-CT: Partly microcrystalline materials which contain predominantly cristobalite in an amorphous matrix.

Opal-C: To a higher degree microcrystalline material with cristobalite and/or tridymite. Opal-CT and opal C are also termed common opal.

Flörke et al. [9] reviewed the nomenclature of micro- and non-crystalline silica minerals. According to their data $\mathrm{H}_{2} \mathrm{O}$ contents of up to 12 wt.\% can be incorporated into 
opals either as hydroxide groups or as molecular water. Opals may contain-besides silica-other hydrated oxides like $\mathrm{Al}_{2} \mathrm{O}_{3}$ or $\mathrm{Fe}_{2} \mathrm{O}_{3}$.

The dissolution of opal was treated in a paper by Abakov et al. [10]. They dissolved an opal with $88 \mathrm{wt} . \%$ silica that possibly contained microcrystalline cristobalite at temperatures up to $175^{\circ} \mathrm{C}$ in $1 \mathrm{M} \mathrm{NaOH}$ and compared it with results obtained when dissolving other silica sources or alumosilicates under the same conditions. In one test with opal a $\mathrm{SiO}_{2}$ concentration of $10.75 \mathrm{~g} \mathrm{SiO}_{2} / 1$ was reached. The authors explain the high solubility of opal by its nanoscaled microstructure. Ordiales [11] patented the hydrothermal synthesis of sodium water glasses from opals. He achieved a $\mathrm{R}_{\mathrm{m}}$ value of 3.3 at a water vapour pressure of $455,000 \mathrm{~Pa}\left(\approx 150^{\circ} \mathrm{C}\right)$.

The objectives of the work presented here were to use opal as a model substance for impure but reactive silica sources like diatomite, flint stone, opal or biogenic silica (e.g. rice husk ash) to investigate their dissolution behaviour under the conditions of water glass production. Since $\mathrm{R}_{\mathrm{m}}$ values up to 2.7 (e.g. Weldes et al. [1]) have been reached by hydrothermal quartz dissolution the investigations presented here aimed at $R_{m}>3$. Additionally, it was intended to discuss the results in terms of chemical solubility to close the gap between solubility studies performed in the context of geochemistry (e.g. [5] [6]) and the high silica concentration observed in sodium water glasses.

\section{Experimental Study}

A common opal from Minas Gerais, Brazil, was used as silica source. The opal materials were processed and characterized by the following means:

- The samples were washed with water containing tensides as washing agents, dried at $150^{\circ} \mathrm{C}$, rinsed again with pure water and dried again. Then the samples were crushed and ground in an agate beaker with a planetary ball mill (Retsch S 1000, Retsch, Haan, Germany) and magnetically freed from abraded steel particles.

- The density of bulk opal was measured by applying Archimedes principle.

- For sieving a vibratory sieve shaker analysette 3 (Fritzsch, Idar-Oberstein, Germany) was applied. The ground opal was classified into different size fractions. Opal powders with diameters $<90 \mu \mathrm{m}$ and opal grains with sizes between 250 and $500 \mu \mathrm{m}$ were used for standard dissolution tests.

- Chemical analysis was done by X-ray fluorescence analysis (Siemens SRS 3000, Siemens, Munich, Germany, now: Bruker AXS GmbH, Karlsruhe, Germany).

- The $\mathrm{H}_{2} \mathrm{O}$ content was determined by thermal analysis (STA 409, Netzsch, Selb, Germany) up to $1400^{\circ} \mathrm{C}$ with a heating rate of $10 \mathrm{~K} / \mathrm{min}$.

- The $\mathrm{H}_{2} \mathrm{O}$ content was characterized also by FT-IR spectrometry (IFS 66, Bruker, Karlsruhe, Germany).

- The structure of the materials was analysed by X-ray diffraction analysis (URD 63, FPM Freiberg, Freiberg, Germany; $\mathrm{CuK} \alpha$ radiation).

- The surface of the particles was investigated by environmental scanning electron microscopy (ESEM XL 30 FEG, Philips, Eindhoven, Netherlands).

- Fracture surfaces of samples with a size of $1.2 \times 1.5 \times 0.1 \mathrm{~cm}^{3}$ before breaking were investigated by atomic force microscopy using an Asylum Research MFP-3D (Oxford Instruments, Santa Barbara, CA, USA) with NSC15-tips (Mikro Masch) in tap- 
ping/semicontact mode to get on the one hand surface topography and on the other hand structural surface information, too.

- The internal porosity was characterized by low-temperature nitrogen adsorption (Sorptomatic 1990, Thermo Scientific, Waltham, MA, USA).

Several dissolution methods like heating the batches in pressure tight containers placed in ovens or heating baths with and without stirring were tried. A few experiments at $30^{\circ} \mathrm{C}$ to $100^{\circ} \mathrm{C}$ were performed with PFA (perfluoro alkoxy alkanes) vessels with a volume of $125 \mathrm{ml}$ which were magnetically stirred inside a heating bath. The most promising method was the vertical rotation of digestion vessels inside a modified cabinet dryer (WTB ED 53, Binder, Germany), which was used for temperatures above $100^{\circ} \mathrm{C}$. The rotation speed of the vessels was 25 rounds per minute. Two different types of digestion vessels were used, each with a volume of $125 \mathrm{ml}$ : PTFE (polytetrafluoro ethylene) lined steel bombs (type: Parr acid digestion bomb, Bomb No. 4748, company: Parr Instrument GmbH, Frankfurt, Germany) for temperatures $\geq 160^{\circ} \mathrm{C}$ and PFA vessels (Savillex, Eden Prairie, MN, USA) for lower temperatures.

Dissolution temperatures between $30^{\circ} \mathrm{C}$ and $220^{\circ} \mathrm{C}$ were applied and the dissolution times ranged from 1 to $20 \mathrm{~h}$. The experiments started at room temperature and ended by rapid cooling by a forced cool air flow inside the drying cabinet. The dissolution time was corrected with respect to a dead time which is due to lower reactivity during heating and cooling the reactors. The dead times ranged between 25 and 90 minutes, depending on temperature, and were determined by evaluation of time dependent dissolution runs.

The following starting materials were used:

- Common opal (Minas Gerais, Brazil, delivered by Rheinischer Mineralienkontor Krantz, Bonn, Germany).

- Deionized water.

- Solid $\mathrm{NaOH}$ (p. a. grade; Carl Roth, Karlsruhe, Germany) for the first experiments.

- Concentrated $\mathrm{NaOH}$ lye (caustic soda lye, Akzo Nobel Industrial Chemicals, Bitterfeld, Germany, purity according to [12]) with a nominal $\mathrm{NaOH}$ content of $50 \mathrm{wt} . \%$. The concentration of this $\mathrm{NaOH}$ brine was checked by titration with $0.5 \mathrm{M} \mathrm{HCl}$ and proved to be $49.5 \mathrm{wt} . \%$.

The following batches have been applied:

- A: Batch consisting of $5 \mathrm{~g}$ opal, $4 \mathrm{~g} \mathrm{NaOH}$ brine and $11 \mathrm{~g} \mathrm{H}_{2} \mathrm{O}$. The particle size was $<90 \mu \mathrm{m}$. Considering the silica content of the applied opal a maximal $\mathrm{R}_{\mathrm{m}}$ value $=3$ would have been obtained.

- B: Like A, but with increased opal content of $6.5 \mathrm{~g}\left(\mathrm{NaOH}\right.$ and $\mathrm{H}_{2} \mathrm{O}$ contents remained constant). The particle size was $<90 \mu \mathrm{m}$. The batch corresponded to $\mathrm{R}_{\mathrm{m}}=$ 3.9.

- C: Like B, but with larger opal particles with a size range from 250 to $500 \mu \mathrm{m}$.

- D: In dissolution tests at $160^{\circ} \mathrm{C}$ the $\mathrm{R}_{\mathrm{m}}$ value was varied between 2.4 and 6.7. The batch contained $8 \mathrm{~g} \mathrm{NaOH}, 22 \mathrm{~g} \mathrm{H}_{2} \mathrm{O}$ and 8 to $20 \mathrm{~g}$ opal with sizes $<90 \mu \mathrm{m}$.

- E: Like D, but with 8 to $20 \mathrm{~g}$ opal with sizes between 250 and $500 \mu \mathrm{m}$.

The batch size was $20 \mathrm{~g}$, for some investigation larger batches of up to $60 \mathrm{~g}$ were used, e. g. to obtain samples for viscosity measurements. The tightness of the containers 
was checked by weighing before and after thermal treatment. After cooling down to room temperature a liquid phase and a residue were separated by vacuum filtration. Pressures between 30 and $50 \mathrm{kPa}$ were applied for nearly quantitative separation without significant evaporation of $\mathrm{H}_{2} \mathrm{O}$. The aim of vacuum filtration was to interrupt ongoing dissolution reactions of finely dispersed silica materials directly after the dissolution tests. A possible concentration change due to evaporation was checked by chemical analysis of a sample before and after vacuum filtration: the silica content of a sample dissolved $20 \mathrm{~h}$ at $160^{\circ} \mathrm{C}$ (batch C) changed from $25.6 \mathrm{wt} . \%$ to $25.9 \mathrm{wt} . \%$, whereas the $\mathrm{Na}_{2} \mathrm{O}$ content remained constant.

The obtained liquids were characterized by:

- Titration with 0.5 mole/l hydrochloric acid to analyze the alkaline content (as $\mathrm{Na}_{2} \mathrm{O}$ ).

- Calcination of the liquid phase by stepwise heating via $100^{\circ} \mathrm{C}$ and $400^{\circ} \mathrm{C}$ to $900^{\circ} \mathrm{C}$ with holding times of $2 \mathrm{~h}$ to determine the residual solids content (RSC). The samples were mixed with calcined quartz sand in order to avoid explosive steam evolution. The difference (RSC minus $\mathrm{Na}_{2} \mathrm{O}$-content) is equal to the nonalkaline oxide content of the solution if nonoxidic impurities can be neglected.

- Detailed chemical analysis of two dissolved samples with inductively coupled plasma mass spectrometry (ICP-MS, ELAN 9000, PerkinElmer, Waltham, MA, USA).

- Since alkali oxides other than $\mathrm{Na}_{2} \mathrm{O}$ could be neglected and the RSC consisted mainly of silica the obtained data could be applied to calculate $\mathrm{SiO}_{2}: \mathrm{Na}_{2} \mathrm{O}$ ratios of the hydrothermally obtained water glasses. The nonalkaline oxide content was then named $\mathrm{SiO}_{2}$ content for convenience.

- Density with a pycnometer (Marienfeld, Lauda-Königshofen, Germany).

- Viscosity (Ubbelohde viscosimeter, Labor-Therm, Germany) and refractive index (Abbe-60-Refractometer, Bellingham + Stanley Ltd., Royal Tunbridge Wells, UK).

- The size colloidal distributions of two samples were characterized with dynamic light scattering (ALV-5000 EPP, ALV, Langen, Germany) after filtration with a 0.45 $\mu \mathrm{m}$ filter.

The solid residues were washed with $\mathrm{H}_{2} \mathrm{O}$ to remove alkali species which might react with $\mathrm{CO}_{2}$ and dried gently at $30^{\circ} \mathrm{C}$. Then they were characterized by:

- X-ray powder diffraction (D8 Advanced X-Ray Diffractometer, Bruker AXS GmbH, Germany).

\section{Results}

\subsection{Characterization of Opal}

The investigated opal was supplied in fist sized pieces with translucent yellowish appearance. Brown veins were separating brighter parts. Figure 1 shows a picture of a specimen. The chemical composition obtained by chemical analysis is listed in Table 1 . The yellowish colour and the brown veins are probably due to $\mathrm{Fe}^{3+}$. The density was $2.14 \pm 0.04 \mathrm{~g} / \mathrm{cm}^{3}$ (standard deviation of 3 samples, accuracy of single measurement < $0.001 \mathrm{~g} / \mathrm{cm}^{3}$ ). The diffraction data (Figure 2) showed the presence of microcrystalline tridymite (major phase), possibly low-quartz and amorphous silica. Line width analysis 
with Scherrers formula (Patterson [13] yielded crystallite sizes of about $10 \mathrm{~nm}$. The water release upon heating was analysed by thermal analysis. The sample lost $2.8 \mathrm{wt} . \%$ up to $200^{\circ} \mathrm{C}$ (accompanied by an exothermic peak), which can be attributed to capillary water. Further mass losses of $1.1 \mathrm{wt} . \%$ between $200^{\circ} \mathrm{C}$ and $500^{\circ} \mathrm{C}$ and $0.8 \mathrm{wt} . \%$ between $500^{\circ} \mathrm{C}$ and $1400^{\circ} \mathrm{C}$ were observed. The total weight loss summarized to $4.7 \mathrm{wt} . \%$. Iler [2] published data on dehydroxylation of silica surfaces and stated that up to $180^{\circ} \mathrm{C}$ absorbed water is set free, whereas at higher temperatures $\mathrm{SiOH}$ groups condensate and liberate molecular $\mathrm{H}_{2} \mathrm{O}$. Between $600^{\circ} \mathrm{C}$ and $700^{\circ} \mathrm{C}$ an accelerated water loss of $0.3 \mathrm{wt} . \%$ within $100 \mathrm{~K}$ was observed, which is connected with the beginning of an exothermic peak. The reason for this accelerated mass loss is seen in structural changes without further investigating it. Low temperature nitrogen adsorption evaluated according to Brunauer, Emmet and Teller [14] yielded a specific surface area of $38 \mathrm{~m}^{2} / \mathrm{g}$. The pores had a size distribution with a maximum at about $35 \mathrm{~nm}$ and occupied a pore volume of $0.024 \mathrm{~cm}^{3} / \mathrm{g}(=5.1 \mathrm{vol} . \%)$. Capillary water in these pores would yield a mass fraction of 2.4 wt. \% which is comparable to the mass loss measured up to $200^{\circ} \mathrm{C}$. FT-IR spectroscopy showed bands typical of molecular water as well as hydroxyl groups connected to the silicate network.

The surface of opal grains was investigated by environmental scanning electron microscopy. Micrographs of different phase ensembles on the surface are shown in Figure 3. The platelike crystallites on the inner side of a larger pore (Figure 3(a)) are probably tridymite crystals whereas Figure 3(b) shows a fracture surface at an higher magnification. Another fracture surface was investigated by atomic force microscopy (Figure 4)

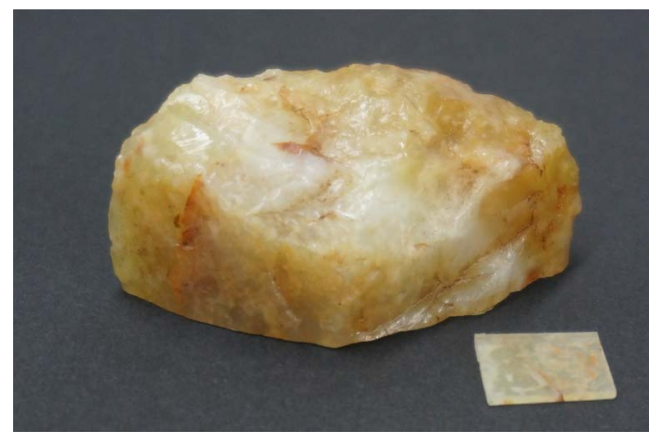

Figure 1. Part of opal specimen; size of platelet (right side): $1.5 \times 1.2 \times 0.1 \mathrm{~cm}^{3}$.

Table 1. Chemical analysis of opal by X-ray fluorescence analysis; $\mathrm{H}_{2} \mathrm{O}$ content was determined by thermal analysis.

\begin{tabular}{cc}
\hline Component & Content in wt.\% \\
\hline $\mathrm{SiO}_{2}$ & 90.9 \\
$\mathrm{Al}_{2} \mathrm{O}_{3}$ & 1.9 \\
$\mathrm{Fe}_{2} \mathrm{O}_{3}$ & 1.5 \\
$\mathrm{CaO}$ & 0.5 \\
$\mathrm{MgO}$ & 0.3 \\
$\mathrm{~K}_{2} \mathrm{O}, \mathrm{TiO}_{2}, \mathrm{SO}_{3}, \mathrm{Cl}, \mathrm{MnO}, \mathrm{ZnO}, \mathrm{CuO}, \mathrm{NiO}, \mathrm{Cr}_{2} \mathrm{O}_{3}, \mathrm{SrO}, \mathrm{BaO}$ & each $<0.1$ \\
$\mathrm{H}_{2} \mathrm{O}$ & 4.7 \\
\hline
\end{tabular}




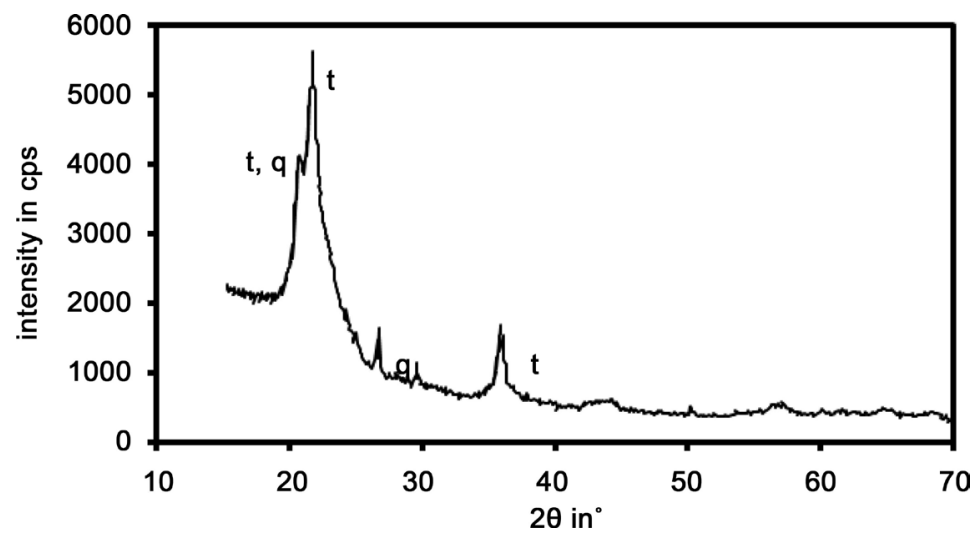

Figure 2. X-ray diffraction pattern of opal; CuK $\alpha$ radiation; t: tridymite (JCPDS 18-1170), q: low-quartz (JCPDS 2-458).

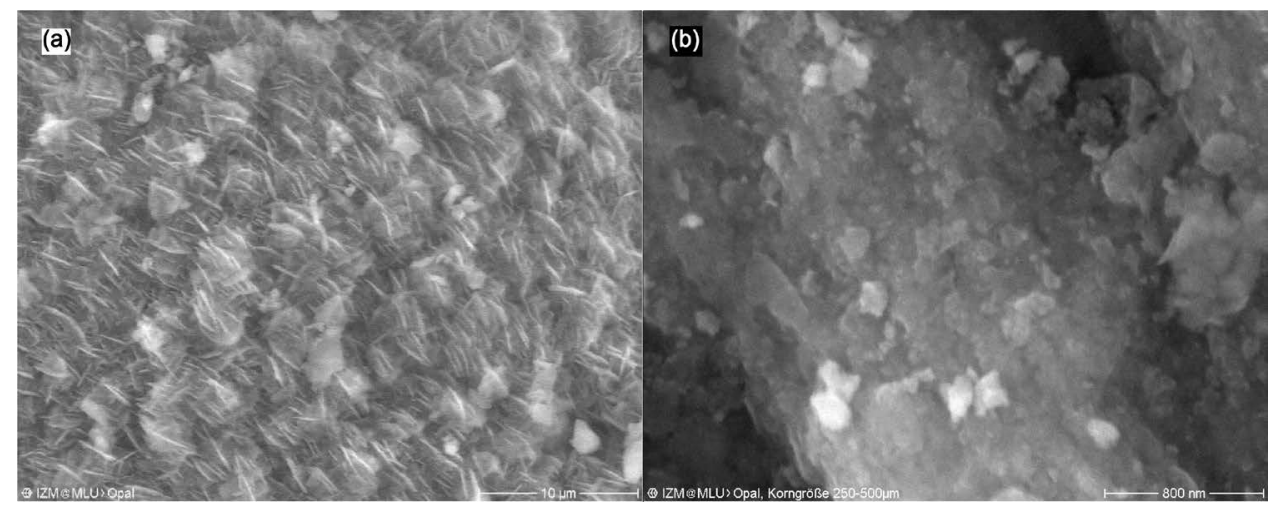

Figure 3. Electron micrographs of common opal; scale bar in the lower right corner; (a) surface inside larger pore, (b) fracture surface.
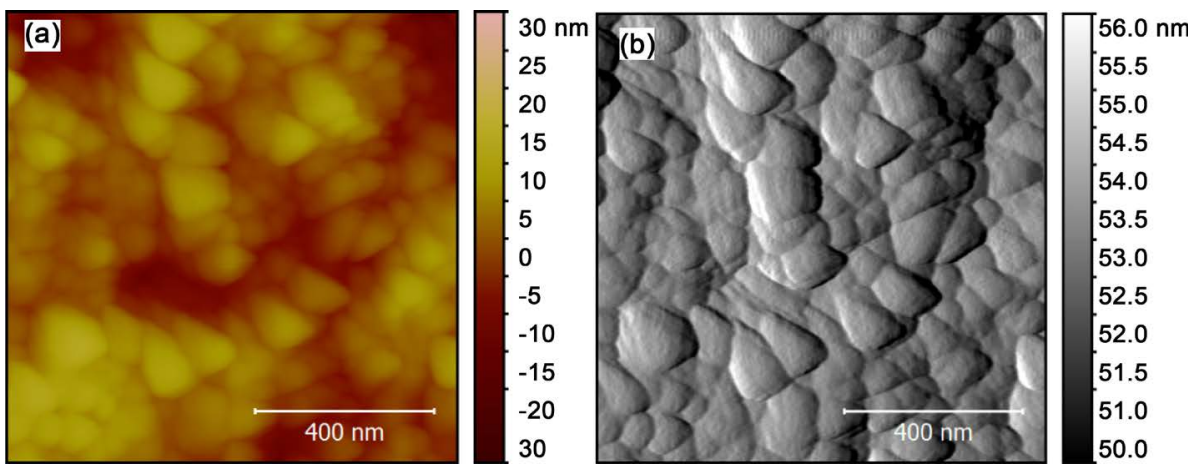

Figure 4. Atomic force microscope image of opal fracture surface; (a) height image, (b) tapping amplitude image measured for structure analyzation; lateral scale bar in the picture, height or deflection scale on right side.

also at higher magnification. Here a random close packing of colloidal particles with sizes of about 50 to measurement. To summarize, the microstructure of the investigated opal is heterogeneous on a 10 to $100 \mathrm{~nm}$ scale. Microcrystalline as well as colloidal microstructures can be identified.

\subsection{Dissolution Tests}

The dissolution tests with opal batches were performed with rotating autoclaves. After 
these dissolution tests the obtained materials were separated into a liquid and a solid phase. $20 \mathrm{~g}$ batches yielded between 10 and $16 \mathrm{~g}$ liquid phase and 4 to $6 \mathrm{~g}$ solid phase. A mass loss of $5 \mathrm{wt} . \%$ to $20 \mathrm{wt} . \%$ of the batch was observed which was mainly due to wall losses caused by the experimental procedure. The vacuum filtration reduced the solid content for about 0.3 wt.\% whereas the $\mathrm{Na}_{2} \mathrm{O}$ content remained constant. This is an indication that filtration has a selective influence on the concentrations. The results are presented in Figures 5-8. As later will be discussed the error range of the silica analysis is between $-0.6 \mathrm{wt} . \%$ and $+0.2 \mathrm{wt} . \%$. The size of the symbols used in Figures 5-8 has approximately that size.

\subsubsection{Time Dependence}

In Figure 5 the time dependence of the silica contents obtained with batch $\mathrm{A}$ at temperatures between $160^{\circ} \mathrm{C}$ and $220^{\circ} \mathrm{C}$ is shown. Usually, the highest silica contents were obtained after $4 \mathrm{~h}$. At longer dissolution times the silica contents decreased and possibly approximated a constant value.

\subsubsection{Dependence on Batch Composition and Particle Size}

In Figure 6 dissolution tests at $200^{\circ} \mathrm{C}$ with batches $\mathrm{A}, \mathrm{B}$, and $\mathrm{C}$ are compared. Dissolu-

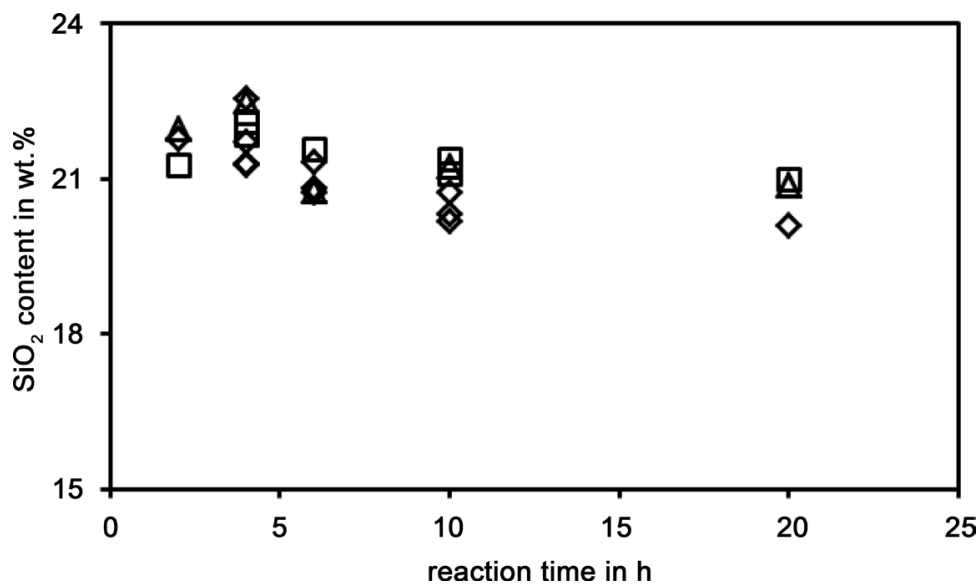

Figure 5. Silica content of liquid phases prepared from batch $\mathrm{A}$ as a function of dissolution time; dissolution temperatures: $\square: 160^{\circ} \mathrm{C}, \diamond: 200^{\circ} \mathrm{C}, \Delta: 220^{\circ} \mathrm{C}$.

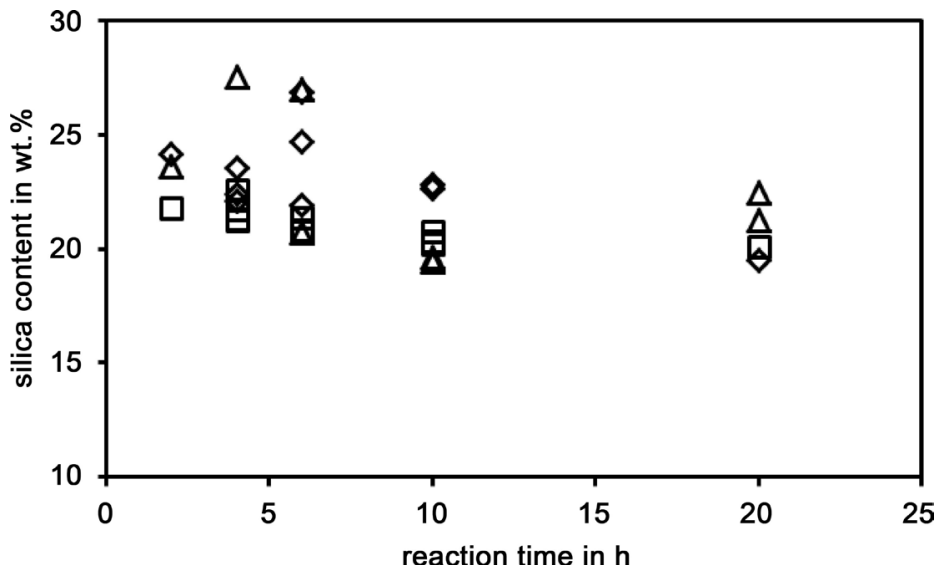

Figure 6. Silica content of liquid phases prepared from batches A $(\square), B(\diamond)$, and $C(\Delta)$ as a function of dissolution time; dissolution temperature $200^{\circ} \mathrm{C}$. 
tion tests with batches $\mathrm{B}$ and $\mathrm{C}$ show a more pronounced maximum of silica contents after 4 or $6 \mathrm{~h}$. On one hand batches B and C contained 30\% more opal. Therefore, the higher silica contents in shorter dissolution runs are possibly due to the higher surface area of the dissolving opal grains. On the other hand, the decrease of grain size from batch $\mathrm{B}$ to batch $\mathrm{C}$ had not the expected effect on kinetics. The decrease of silica content in longer dissolution tests, parallel to observations discussed in connection with Figure 5, leads to the assumption that there is a solubility limitation.

\subsubsection{Temperature Dependence}

Figure 7 compares the maximal $\mathrm{SiO}_{2}$ contents obtained with batches $\mathrm{B}$ and $\mathrm{C}$ as a function of temperature. The maximal $\mathrm{SiO}_{2}$ contents obtained with batch $\mathrm{C}$ increase with Temperature except at $220^{\circ} \mathrm{C} \mathrm{B}$. In the case of batch $\mathrm{C}$ the maximal $\mathrm{SiO}_{2}$ contents decrease with temperature, whereas they generally increase with temperature. The final values of the $\mathrm{SiO}_{2}$ contents obtained with batch $\mathrm{A}$ are included in the diagram for comparison. It is supposed that these long term silica concentrations are closer to equilibrium values. Then the maximal values ("overshot") are due to dissolution kinetics and can be governed by the grain size or surface area of the dissolving opal. The experiences with batches $\mathrm{B}$ and $\mathrm{C}$ indicated that a surplus of silica enhances the achievable silica concentrations.

\subsubsection{Dependence on $\mathbf{R}_{\mathrm{m}}$}

Therefore, the $R_{m}$ values of the starting materials were varied over a wide range between 2.4 and 6.7 in batches D and E. The results are shown in Figure 8. With batch D as well as with batch $\mathrm{E}$ the silica contents approach constant values of about $25 \mathrm{wt} . \%$ and the $R_{m}$ and approach values of about 3.5, respectively, with increasing initial $R_{m}$ value of the batch. This shows that compositions close to commercial water glasses with $\mathrm{R}_{\mathrm{m}}=3.3$ can be reproducibly obtained if reactive starting materials are used. The concentration values reached with batches D and E within $6 \mathrm{~h}$ are higher than the long term values reached with batch A (included in Figure 7). Thus, these high values do not present equilibrium values.

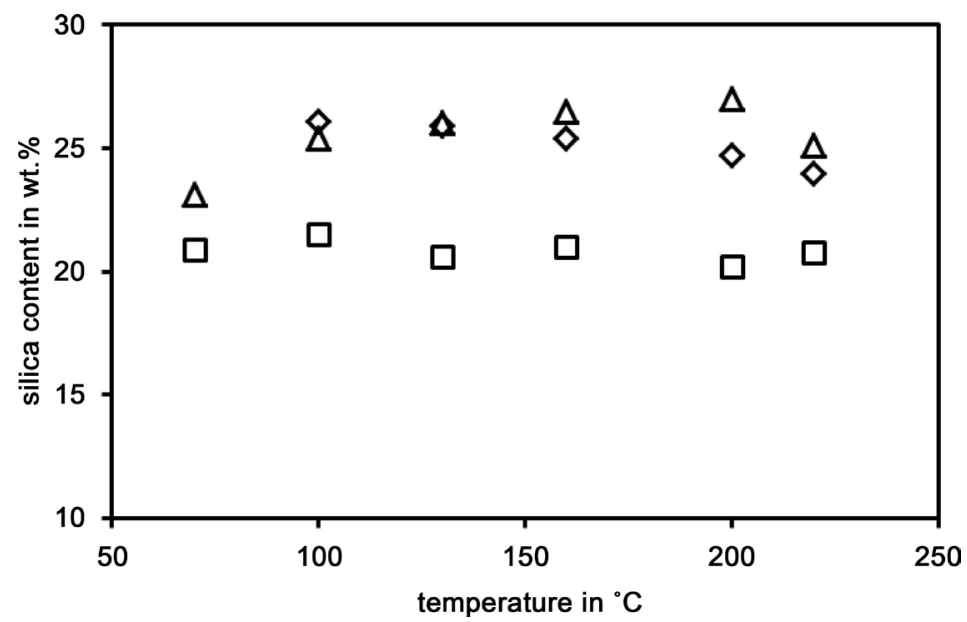

Figure 7. Maxima of silica contents of liquid phases prepared from batches $B(\diamond)$ and $C(\Delta)$ as a function of dissolution temperature; dissolution times $4 \mathrm{~h}$ or $6 \mathrm{~h}$; final value of silica content of liquid phase prepared from batch $A(\square)$ at that these temperatures included for comparison. 


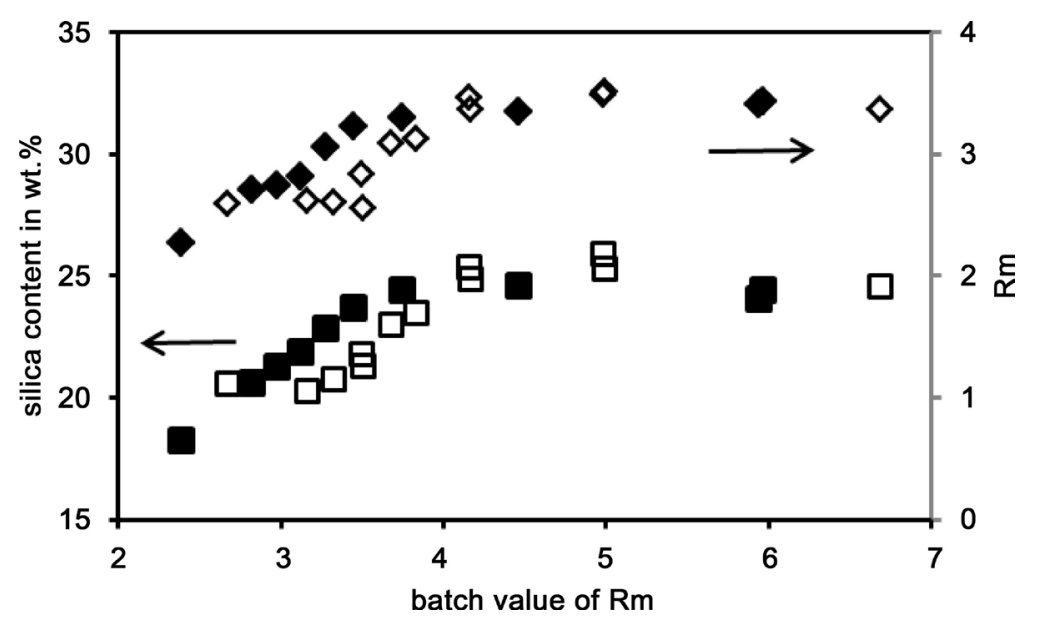

Figure 8. Silica content ( $\mathbf{\square}$ : batch $\mathrm{D}, \square$ : batch E) and measured values of $\mathrm{R}_{\mathrm{m}}(\diamond$ : batch $\mathrm{D}, \diamond$ : batch $\mathrm{E}$ ) of liquid phases as a function of the initial $\mathrm{R}_{\mathrm{m}}$ value; dissolution time $6 \mathrm{~h}$; dissolution temperature $160^{\circ} \mathrm{C}$.

\subsection{Characterization of the Products}

Some of the findings reported above made it necessary to characterize the dissolution products in detail. The chemical composition of two liquid phases with a composition close to commercial sodium water glasses were analysed additionally with inductively coupled plasma spectroscopy. The results are shown in Table 2. The $\mathrm{Na}_{2} \mathrm{O}$ content was measured by two different methods and allows a control of the analysis: the difference of the results is $<0.3 \mathrm{wt} . \%$. The sum of the "impurities" (nonalkaline oxides minus $\mathrm{SiO}_{2}$ ) is less than $0.3 \mathrm{wt} . \%$. Therefore, the silica content of the "nonalkaline oxides" is larger than $98 \mathrm{wt} . \%$. Together with the observed up concentration of silica by vacuum filtration the measured "silica" contents are about $0.6 \mathrm{wt} . \%$ too high. Thus the error range of the silica determination is $-0.6 \mathrm{wt} . \%$ to $+0.2 \mathrm{wt} \%$. A comparison of the liquid phase composition with the opal composition (Table 1) reveals that the concentration of the impurities is remarkably reduced the $\mathrm{Al}_{2} \mathrm{O}_{3}$ content by a factor of 2.5 and the $\mathrm{Fe}_{2} \mathrm{O}_{3}$ content by a factor $>10$.

Basic properties of the obtained liquids are compared in Table 3 with literature data (Roggendorf et al. [15]). Density and refractive index agree very well whereas the viscosities deviate to a certain degree. This deviation is due to the lower alkaline contents (Weldes and Lange [1]) of the water glasses prepared here from opal.

The solid residues contain crystalline phases and probably remnants of the dissolved opal. In a few cases gel-like materials were formed as dissolution remnants, especially at intermediate temperatures and high initial $\mathrm{R}_{\mathrm{m}}$ values. The solid residues of two dissolution tests were investigated by X-ray diffraction. One sample was made from batch $\mathrm{B}$, and was treated $20 \mathrm{~h}$ at $220^{\circ} \mathrm{C}$. The liquid phase contained $18.5 \mathrm{wt} . \% \mathrm{SiO}_{2}$ and $7.8 \mathrm{wt} . \%$ $\mathrm{Na}_{2} \mathrm{O}$. The diffraction pattern is shown in Figure 9. The second sample was made from batch $\mathrm{C}$ and treated under comparable conditions. In this sample the liquid phase contained 19.3 wt. $\% \mathrm{SiO}_{2}$ and $8.1 \mathrm{wt} . \% \mathrm{Na}_{2} \mathrm{O}$. The diffraction patterns of both samples were nearly identical. The major phase was low-quartz which was accompanied by analcime, a zeolite occurring in nature with the chemical formula $\mathrm{Na}\left[\mathrm{AlSi}_{2} \mathrm{O}_{6}\right] \cdot \mathrm{H}_{2} \mathrm{O}$. The crystallization of analcime is probably responsible for the reduction of the alumina content of 
the liquid phase in comparison to the starting materials. A water glass made by dissolving batch $\mathrm{C}$ for $20 \mathrm{~h}$ at $160^{\circ} \mathrm{C}$ was investigated by dynamic light scattering. The sample had a silica content of $25.6 \mathrm{wt} . \%$ and $\mathrm{R}_{\mathrm{m}}=3.53$. Colloidal particles with a

Table 2. Chemical analysis data of two solutions prepared by dissolving opal in $\mathrm{NaOH}$ lye; $\mathrm{Na}_{2} \mathrm{O}$ is determined by titration and the other elements (including $\mathrm{Na}$ ) by ICP-MS; Main elements are converted to oxide components for comparison; dissolution temperature: $160^{\circ} \mathrm{C}$; dissolution time: $6 \mathrm{~h}$; opal contents $15 \mathrm{~g}$ (batch D) and $12.5 \mathrm{~g}$ (batch E).

\begin{tabular}{|c|c|c|c|c|c|}
\hline Batch & $\mathrm{D}$ & $\mathrm{E}$ & & $\mathrm{D}$ & $\mathrm{E}$ \\
\hline \multicolumn{3}{|c|}{ Titration with $\mathrm{HCl}$ : } & \multicolumn{3}{|c|}{ Recalculated from ICP } \\
\hline $\mathrm{Na}_{2} \mathrm{O}$ in wt.\% & 7.59 & 7.63 & component & Cont & wt.\% \\
\hline \multicolumn{3}{|c|}{ Loss on ignition: } & $\mathrm{Na}_{2} \mathrm{O}$ & 7.32 & 7.51 \\
\hline $\mathrm{SiO}_{2}$ in wt.\% & 24.6 & 24.9 & $\mathrm{Al}_{2} \mathrm{O}_{3}$ & 0.25 & 0.16 \\
\hline $\mathrm{R}_{\mathrm{m}}$ & 3.34 & 3.37 & $\mathrm{Fe}_{2} \mathrm{O}_{3}$ & 0.04 & 0.03 \\
\hline \multicolumn{6}{|l|}{ ICP analysis } \\
\hline Element & in ppm & in $\mathrm{ppm}$ & Element & in ppm & in ppm \\
\hline $\mathrm{Na}$ & 54,300 & 55,700 & $P$ & 10 & 10 \\
\hline $\mathrm{Al}$ & 1340 & 870 & K & 10 & 10 \\
\hline $\mathrm{Fe}$ & 310 & 220 & $\mathrm{Mg}$ & 10 & 10 \\
\hline $\mathrm{Ca}$ & 130 & 160 & $\mathrm{Zn}$ & 4 & 3 \\
\hline $\mathrm{Ba}$ & 90 & 20 & $\mathrm{La}$ & 5 & 3 \\
\hline $\mathrm{Nd}$ & 20 & 20 & $\mathrm{Sr}$ & 4 & 3 \\
\hline $\mathrm{Ce}$ & 40 & 10 & $\mathrm{~V}$ & 2 & 1 \\
\hline $\mathrm{Sc}$ & 20 & 20 & $\operatorname{Pr}$ & 1 & 1 \\
\hline $\mathrm{Ti}$ & 10 & 4 & $\mathrm{Mn}$ & 1 & 1 \\
\hline $\mathrm{Zr}$ & 10 & 10 & & & \\
\hline
\end{tabular}

Table 3. Basic properties of obtained water glass prepared with batch E compared with literature data obtained by dissolving a sodium silicate glass; the opal content is related to $20 \mathrm{~g}$ batch, two $40 \mathrm{~g}$ batches were treated simultaneously and mixed before analysis in order to produce enough liquid phase.

\begin{tabular}{ccc}
\hline Batch & $\mathrm{E}$ & Sodium silicate glass [21] \\
\hline Opal in g & 6.25 & 140 \\
Dissolved at $\left(\right.$ in $\left.{ }^{\circ} \mathrm{C}\right)$ & 160 & 5 \\
Dissolution time in $\mathrm{h}$ & 6 & 8.0 \\
$\mathrm{Na}_{2} \mathrm{O}$ in wt. \% & 7.56 & $25.2\left(\mathrm{SiO}_{2}\right)$ \\
Nonalkaline oxides in wt. \% & 25.41 & 3.21 \\
$\mathrm{R}_{\mathrm{m}}$ & 3.47 & 21 \\
Viscosity in mPa.s & $29.3 \pm 0.5\left(20.9^{\circ} \mathrm{C}\right)$ & 1.387 \\
Refractive index & $1.3867 \pm 0.0003\left(21.7^{\circ} \mathrm{C}\right)$ & 1.327 \\
Density in $\mathrm{g} \cdot \mathrm{cm}^{-3}$ & $1.325 \pm 0.0013\left(21.1^{\circ} \mathrm{C}\right)$ & \\
\hline
\end{tabular}




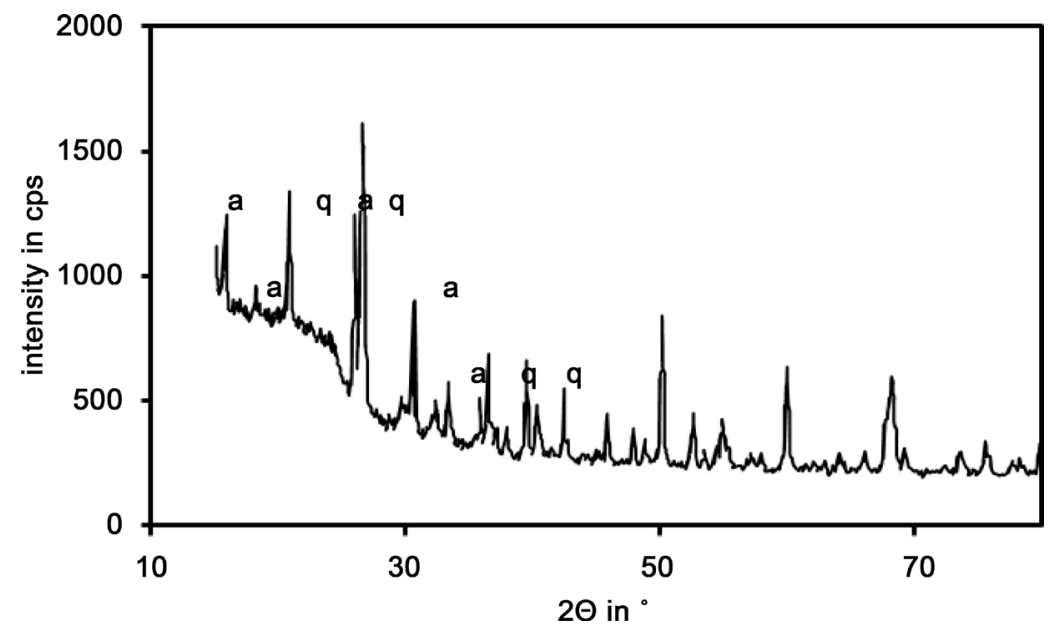

Figure 9. X-ray diffraction pattern of solid residue after hydrothermal treatment of opal in $\mathrm{NaOH}$ lye; batch $\mathrm{B}$, dissolution temperature: $220^{\circ} \mathrm{C}$; dissolution time: $20 \mathrm{~h}$; nonalkaline oxide content: 18.5 wt. $\%, \mathrm{Na}_{2} \mathrm{O}: 7.8$ wt. $\%, \mathrm{R}_{\mathrm{m}}=2.44$; $\mathrm{CuK} \alpha$ radiation; a: analcime $\left(\mathrm{Na}\left[\mathrm{AlSi}_{2} \mathrm{O}_{6}\right] \cdot \mathrm{H}_{2} \mathrm{O}\right.$; JCPDS 2-340), q: low-quartz (JCPDS 2-458).

monomodal size distribution at a radius of $1.6 \mathrm{~nm}$ were found. These particles are larger than the "primary" colloids found by Böschel et al. [16]. But the larger sizes interpreted as aggregates in that reference, were not found.

\section{Discussion}

Opal is an unlikely raw material for water glass production. Nevertheless, it can serve as model for other microcrystalline or amorphous silica sources. The material used in this study is an Opal-CT with a microstructure consisting of microcrystalline tridymite, traces of low-quartz, and amorphous parts build up by random packings of size distributed amorphous silica colloids. Further, it has an internal porosity and an appreciable specific surface area. All these features of the microstructure may contribute to the fast dissolution under hydrothermal conditions. The dissolution conditions were inspired by the hydrothermal synthesis of water glass synthesis by dissolving silica. High concentrations of $\mathrm{SiO}_{2}$ in the liquid phase were reached already after short dissolution times. Therefore, it was not possible to evaluate the kinetics of the early stages of the dissolution process.

In dissolution test with varied initial $\mathrm{R}_{\mathrm{m}}$ value it was found that a higher amount of initial silica is needed to reach comparable silica concentrations within the fixed dissolution time, but the deviation is rather small. Therefore, it is concluded that the use of coarser opal grains did not significantly slow down the dissolution process as it was initially hoped. The effects of particle size and specific surface area on dissolution rates was discussed by Diedrich et al. [17] who made aggregation of very small particles, lacking etch pits or different concentrations of reactive surface groups responsible for surface normalized dissolution rates increasing with particle size.

Most of the test runs were evaluated by titration (yielding $\mathrm{Na}_{2} \mathrm{O}$ contents, other alkalis were only found in traces in chemical analysis) and determination of the solids content via calcination. The "nonalkaline oxides" obtained by subtraction (solid content minus $\mathrm{Na}_{2} \mathrm{O}$ content) consisted mainly of $\mathrm{SiO}_{2}$, more than 98 wt.\% $\mathrm{SiO}_{2}$ were found in 
chemical analysis. This allows the comparison with commercially produced sodium water glasses. The vacuum filtration which was applied to stop the dissolution reaction after the test run increases the uncertainty level by further $0.3 \mathrm{wt} . \%$.

The starting materials contain appreciable amounts of $\mathrm{Al}_{2} \mathrm{O}_{3}$ and $\mathrm{Fe}_{2} \mathrm{O}_{3}$ as impurities. The purity of the liquid phase was enhanced by crystallization of analcime. This phase crystallizes under hydrothermal conditions and contains $\mathrm{Al}$ in its chemical formula. Additionally, it can incorporate some amounts of iron [18] and serve as adsorbent for cations [19]. The main crystalline phase precipitating during the dissolution tests was low-quartz. It is probable that an equilibrium state saturated with respect to low-quartz is approached. This would also explain the observed concentration development with time which seems to pass a maximum and approaches constant values for the long term. It is therefore supposed that the minimal values obtained especially with batch A are close to the equilibrium solubility of low - quartz under hydrothermal conditions at quite high $\mathrm{pH}$ values. These solutions have $\mathrm{pH}$ values of about 12 after cooling down to room temperature [15]. The $\mathrm{SiO}_{2}$ concentrations are higher than those calculated from available thermodynamic data (Fleming et al. [5]), but in these studies only monomeric silicate molecules or anions and not the colloidal silica were taken into account.

The higher limits of silica concentrations of about $25 \mathrm{wt} . \%$ to $27 \mathrm{wt} . \%$ might have different causes. They might be typical values of critical limiting supersaturation according to La Mer [20], restricted by viscosity, or caused by solubility limitations due to another phase. Additionally, the colloidal fraction might contribute to the solubility equilibrium.

To answer some of these questions, dissolution tests with quartz and amorphous silica were performed and will be evaluated in future publications.

\section{Conclusion}

Common opal was used as silica source for hydrothermal water glass production. At temperatures between $100^{\circ} \mathrm{C}$ and $220^{\circ} \mathrm{C}$ high silica contents of about $25 \mathrm{wt} . \%$ and $\mathrm{R}_{\mathrm{m}}$ values above 3.0 were reached with 4 to $6 \mathrm{~h}$. The obtained water glasses are comparable to commercials products. At longer dissolution times, the silica concentration of the water glasses decreased and probably approached concentration limitation of silica of about $20 \mathrm{wt} . \%$ to $22 \mathrm{wt}$.\% nearly independent of temperature due to a solubility equilibrium. The colloidal fraction might be involved in this equilibrium. The identification of a solubility equilibrium explaining the observed concentration limitations is regarded as new aspect in discussing the chemistry of water glasses. The applied common opal contained appreciable impurity concentrations, especially iron oxide and alumina. Due to crystallization and possibly adsorption at crystallization products (e.g. analcime) the impurity level of the obtained liquid water glasses was remarkably reduced. Low-quartz was identified as major crystalline phase of the solid residue and is supposed to control solubility.

\section{Acknowledgements}

The authors gratefully thank S. Brinke and H. Schwalbe (experimental support), S. Sander (dynamic light scattering), B. Niehus (CP-MS analysis), J. Bienias (porosimetry 
measurements), Dr. N. Kilian (X-ray diffraction), Dr. A. Hauser (atomic force microscopy), F. Syrowatka (scanning electron microscopy) and the work shop of the institute of physics, especially H. Benkwitz, for building the rotation device for steel autoclaves.

\section{References}

[1] Weldes, H.H. and Lange, K.R. (1969) Properties of Soluble Silicates. Journal of Industrial and Engineering Chemistry, 61, 29-44. https://doi.org/10.1021/ie50712a008

[2] Iler, R.K. (1979) Chemistry of Silica. Wiley-Interscience, New York.

[3] Stöber, W. (1966) Physical and Chemical Properties of Coesite and Stishovite Compared to Quartz (Translated from German). Beitr. Silikoseforschung, 89, 1-113.

[4] Dove, P.M. and Rimstidt, J.D. (1994) Silica-Water Interactions. In: Prewitt, P.J., et al., Eds., Reviews in Mineralogy, Vol. 29, Silica-Physical Behavior, Geochemistry and Materials Applications, Mineralogical Society of America, Washington DC, 259-308.

[5] Fleming, B.A. and Crerar, D.A. (1982) Silicic Acid Ionization and Calculation of Silica Solubility at Elevated Temperature and $\mathrm{pH}$ Application to Geothermal Fluid Processing and Reinjection. Geothermics, 11, 15-29. https://doi.org/10.1016/0375-6505(82)90004-9

[6] Gunnarsson, I. and Arnorsson, S. (2000) Amorphous Silica Solubility and the Thermodynamic Properties of $\mathrm{H}_{4} \mathrm{SiO}_{4}$ in the Range of $0^{\circ}$ to $350^{\circ} \mathrm{C}$ at Psat. Geochimica et Cosmochimica Acta, 64, 2295-2307. https://doi.org/10.1016/S0016-7037(99)00426-3

[7] Tuttle, O.F.A. and Friedmann, I.I. (1948) Liquid Immiscibility in the System $\mathrm{H}_{2} \mathrm{O}-\mathrm{Na}_{2} \mathrm{O}-$ $\mathrm{SiO}_{2}$. Journal of the American Chemical Society, 70, 919-926.

https://doi.org/10.1021/ja01183a011

[8] Jones, J.B. and Segnit, E.R. (1971) The Nature of Opal. I. Nomenclature and Constituent Phases. Journal of the Geological Society of Australia, 18, 57-68. https://doi.org/10.1080/00167617108728743

[9] Flörke, O.W., Graetsch, H., Martin, B. and Wirth, R. (1991) Nomenclature of Micro- and Non-Crystalline Silica Materials-Based on Structure and Microstructure. Neues Jahrbuch für Mineralogie Abhandlungen, 163, 19-42.

[10] Avakov, V.A. and Vinogradow, B.N. (1974) Comparative Solubility of Silica and Some Alumosilicates (Title Translated from Russian). Izvestiya Vysshikh Uchebnykh Zavedenii, Khimiya i Khimicheskaya Tekhnologiya, 17, 879-882.

[11] Ordiales, E. (1969) Production of Alkali Silicates from Opal and Similar Minerals (Translated from German). German Patent DE 1969-1900066.

[12] DIN EN 896 (2012) Chemicals Used for Treatment of Water Intended for Human Consumption-Sodium Hydroxide. Beuth Verlag, Berlin.

[13] Oelkers, E.H., Helgeson H.C., Shock, E.L., Sverjensky, D.A., Johnson, J.W.A. and Pokrovskii, V.A. (1994) Summary of the Apparent Partial Molal Standard Gibbs Free Energies of Aqueous Species, Minerals, and Gases at Pressures 1 to 5000 Bars and Temperatures 25 to $1000{ }^{\circ} \mathrm{C}$. Journal of Physical and Chemical Reference Data, 24, 1401-1560.

[14] Patterson, A.L. (1939) The Scherrer Formula for X-Ray Particle Size Determination. Physical Review, 56, 978-982. https://doi.org/10.1103/PhysRev.56.978

[15] Brunauer, S., Emmet, P.H. and Teller, E. (1938) Adsorption of Gases in Multimolecular Layers. Journal of the American Chemical Society, 60, 309-319. https://doi.org/10.1021/ja01269a023

[16] Roggendorf, H., Grond, W. and Hurbanic, M. (1996) Structural Characterization of Concentrated Alkaline Silicate Solutions by ${ }^{29} \mathrm{Si}$-NMR Spectroscopy, FT-IR Spectroscopy, Light Scattering, and Electron Microscopy-Molecules, Colloids and Artefacts. Glass Science and Technology, 69, 216-231.

[17] Böschel, D., Janich, M. and Roggendorf, H. (2003) Size Distribution of Colloidal Silica in 
Sodium Silicate Solutions Investigated by Dynamic Light Scattering and Viscosity Measurements. Journal of Colloid and Interface Science, 267, 360-368.

https://doi.org/10.1016/j.jcis.2003.07.016

[18] Diedrich, T., Dybowska, A., Schott, J., Valsami-Jones, E. and Oelkers, E.H. (2012) The Dissolution of $\mathrm{SiO}_{2}$ Nanoparticles as a Function of Particle Size. Environmental Science \& Technology, 46, 4909-4915. https://doi.org/10.1021/es2045053

[19] Azizi, S.N. and Yousefpour, M. (2011) Isomorphous Substitution of Iron and Nickel into Analcime Zeolite. Zeitschrift für anorganische und allgemeine Chemie, 637, 759-765. https://doi.org/10.1002/zaac.201100059

[20] Jannagadha Rao, M. and Gopal Krishna, B. (2013) Naturally Engineered Analcime for Water Treatment Process and Its Calorimetric Properties. International Journal of Science and Research, 160-166.

[21] La Mer, V.K. (1952) Nucleation in Phase Transitions. Industrial \& Engineering Chemistry, 44, 1270-1277. https://doi.org/10.1021/ie50510a027

Submit or recommend next manuscript to SCIRP and we will provide best service for you:

Accepting pre-submission inquiries through Email, Facebook, LinkedIn, Twitter, etc.

A wide selection of journals (inclusive of 9 subjects, more than 200 journals)

Providing 24-hour high-quality service

User-friendly online submission system

Fair and swift peer-review system

Efficient typesetting and proofreading procedure

Display of the result of downloads and visits, as well as the number of cited articles Maximum dissemination of your research work

Submit your manuscript at: http://papersubmission.scirp.org/

Or contact aces@scirp.org 